\title{
Research of Impact Load in Large Electrohydraulic Load Simulator
}

\author{
Yongguang Liu, Xiaohui Gao, and Zhongcai Pei \\ School of Automation Science and Electrical Engineering, Beihang University, Beijing 100191, China \\ Correspondence should be addressed to Xiaohui Gao; hgaoxiaohui@126.com
}

Received 7 July 2014; Revised 26 July 2014; Accepted 26 July 2014; Published 18 August 2014

Academic Editor: Hui Zhang

Copyright (C) 2014 Yongguang Liu et al. This is an open access article distributed under the Creative Commons Attribution License, which permits unrestricted use, distribution, and reproduction in any medium, provided the original work is properly cited.

The stronger impact load will appear in the initial phase when the large electric cylinder is tested in the hardware-in-loop simulation. In this paper, the mathematical model is built based on AMESim, and then the reason of the impact load is investigated through analyzing the changing tendency of parameters in the simulation results. The inhibition methods of impact load are presented according to the structural invariability principle and applied to the actual system. The final experimental result indicates that the impact load is inhibited, which provides a good experimental condition for the electric cylinder and promotes the study of large load simulator.

\section{Introduction}

Electrohydraulic load simulator gets favor of many experts because of its fast response, high precision, good dynamic performance, high power, and interference rejection [1-4]. Since there are many nonlinear factors in the electrohydraulic servo system, such as load disturbance, friction, and asynchronous response, how to overcome them becomes the research focus. Some experts have greatly improved the dynamic response performance of the electrohydraulic system through advanced control algorithm [5-8], but they pay more attention to the dynamic tracking process and ignore the initial stage. The electrohydraulic load simulator is a kind of passive loading way and the extra force will appear due to the asynchronous response of two actuators. Many control methods are proposed to suppress the extra force to improve the dynamic tracing precision [9-16]. These control methods can reduce the amplitude of extra force to some extent, but it is difficult to apply them to the high precision real-time control system because of their complexity. The impact load that is a kind of extra force will appear in the initial phase when electric cylinder is tested in the hardwarein-loop simulation, which seriously reduces the dynamic loading precision and may destroy the electric cylinder. Therefore, it is necessary to research the principle of the impact load and adopt some simple control methods which can be applied in the high precision real-time control system.

\section{Large Electrohydraulic Load Simulator}

Large electrohydraulic load simulator is applied to simulate load in the rising process of the missile launcher to test the performance of electric cylinder. This test bed consists of experiment platform, measurement and control system, and hydraulic system, which can provide $100 \mathrm{t}$ (ton) loading force, $100 \mathrm{~mm} / \mathrm{s}$ velocity, and $0-5 \mathrm{~m}$ loading range. $100 \mathrm{t}$ hydraulic servo cylinder, support, rail guided vehicle, and $30 \mathrm{t}$ electric cylinder compose the platform (Figure 1). The LabWindows, that is, a kind of configuration software, is applied to be an upper computer in the measurement and control system, which is applied to issue instructions and display sampling data. The real-time control system adopts RTX whose control period is $1 \mathrm{~ms}$. Hydraulic system can provide $21 \mathrm{MPa}$ pressure and $300 \mathrm{~L} / \mathrm{min}$ flow. The load response curve of the electrohydraulic load simulator is shown in Figure 2. It can be seen that the impact load is up to $40 \mathrm{t}$ in the initial stages of loading which has been far beyond the limit load of $30 \mathrm{t}$ electric cylinder. Therefore, it is necessary to research the reason and inhibition methods of the impact load. 


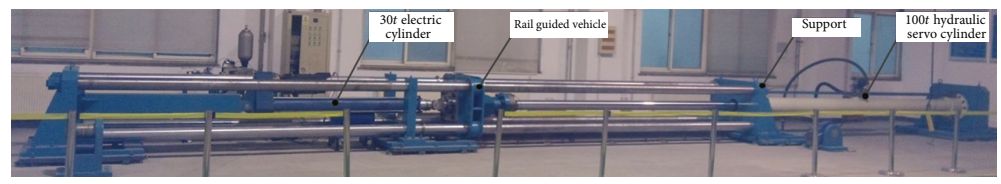

FIGURE 1: Large electrohydraulic load simulator test bed.

TABLE 1: Main parameters of position servo system.

\begin{tabular}{lccc}
\hline$K_{e} /\left(\mathrm{V} \cdot(\mathrm{radps})^{-1}\right)$ & $K_{m} /\left(\mathrm{N} \cdot \mathrm{m} \cdot \mathrm{A}^{-1}\right)$ & $L_{a} / \mathrm{H}$ & $R_{a} / \Omega$ \\
\hline 1.691 & 2.7 & 0.0025 & 0.058 \\
$J_{b} /\left(\mathrm{kg} \cdot \mathrm{m}^{2}\right)$ & $f_{b} /\left(\mathrm{N} \cdot \mathrm{m} \cdot(\mathrm{radps})^{-1}\right)$ & $P_{h} / \mathrm{m}$ & $f_{c}$ \\
0.012 & 0.0063 & 0.02 & 0.3 \\
$f_{a} /\left(\mathrm{N} \cdot \mathrm{m} \cdot(\mathrm{radps})^{-1}\right)$ & $J_{a} /\left(\mathrm{kg} \cdot \mathrm{m}^{2}\right)$ & $i$ & $M_{c} / \mathrm{kg}$ \\
0.0016 & 0.0495 & 12 & 1200 \\
\hline
\end{tabular}

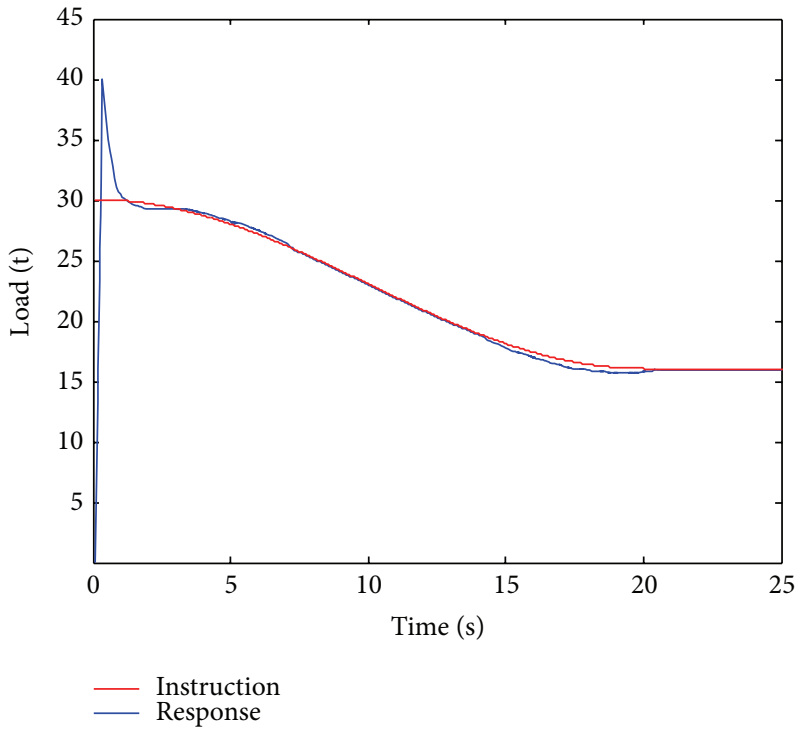

FIGURE 2: Dynamic load response.

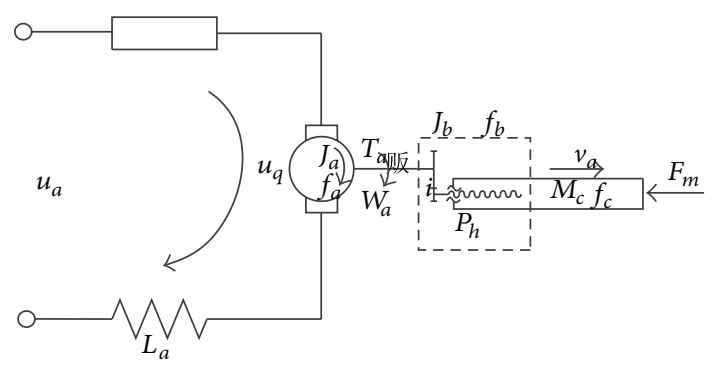

Figure 3: Model of electric cylinder.

\section{Modeling and Simulation Based on AMESim}

The test bed is a synthetic system consisting of mechanism, hydraumatic, measurement and control, which can be divided into position servo system and load simulation servo system. Firstly we, respectively, build mathematic model for the servo system based on AMESim. Then the parameters are set and adjusted to keep consistency between experiment and simulation curve. Finally, we get the mathematic model of the test bed through combining two servo systems. This model will be applied to analyze the reason of the impact load and design controller.

3.1. Modeling and Simulation of the Position Servo System. Position servo system is to control the position of electric cylinder without load. The electric cylinder is composed of servo motor, gear reducer, screw, and piston rod and its transmission model is shown in Figure 3 [16-19]. Equation (1) shows the mathematic model of the position servo system and the block diagram is shown in Figure 4. The main parameters are shown in Table 1. When the position instruction is $100 \mathrm{~mm}$ and the load instruction (Fm) is $0 \mathrm{t}$, the experiment and simulation response curves are shown in Figure 5. It indicates the correctness of this model. Consider

$$
\begin{gathered}
u_{a}-u_{q}=i_{a} R_{a}+L_{a} \frac{d i_{a}}{d t}, \\
T_{a}-T_{b}=J_{a} \frac{d^{2} \theta_{a}}{d t}+f_{a} \frac{d \theta_{a}}{d t}, \\
u_{q}=K_{e} \frac{d \theta_{a}}{d t}, \\
T_{b}-T_{m}=J_{b} \frac{d^{2} \theta_{a}}{d t}+f_{b} \frac{d \theta_{a}}{d t}, \\
T_{m}-\frac{F_{m} P_{h}}{2 \pi \eta i}=M_{c} \frac{d^{2} l_{a}}{d t}+f_{c} \frac{d l_{a}}{d t}, \\
l_{a}=\frac{\theta_{a} P_{h}}{2 \pi i},
\end{gathered}
$$

where $l$ is the position instruction; $w$ is the rotate speed instruction of servo motor, $u_{a}$ is the input voltage of the armature winding; $i_{a}$ is the current of the armature winding; $R_{a}$ is the resistance of the armature winding; $K_{m}$ is the electromagnetic torque coefficient; $K_{e}$ is the voltage coefficient; $T_{a}$ is the electromagnetic torque of the motor shaft; $T_{b}$ is the output moment of motor; $T_{m}$ is the output moment of electric 


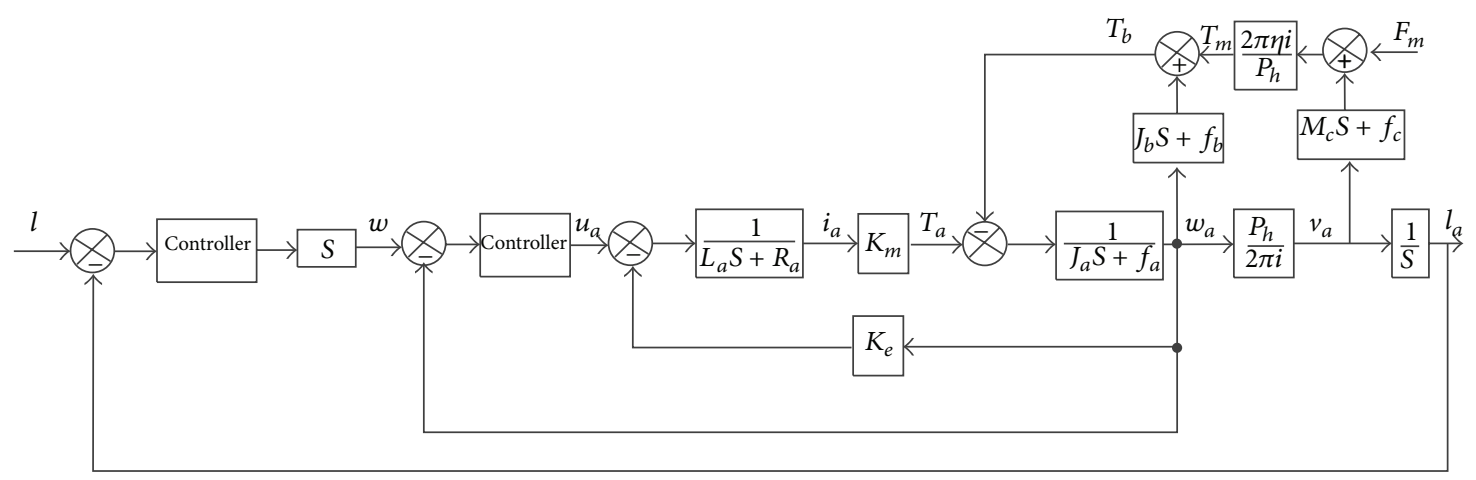

FIGURE 4: Block diagram of position servo system.

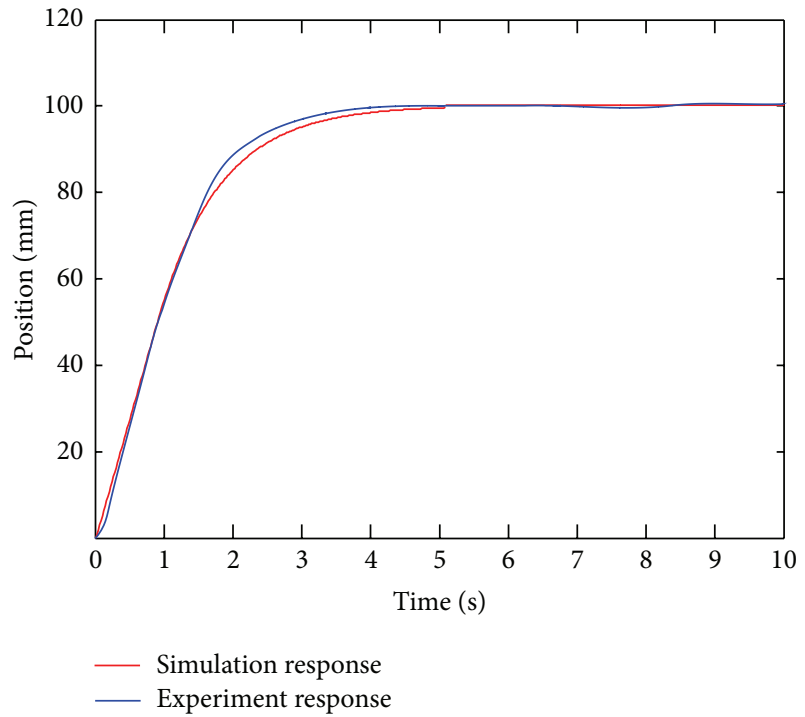

Figure 5: Response of the position servo system.

cylinder; $J_{a}$ is the moment of inertia of the motor shaft; $f_{a}$ is the viscous friction coefficient of the motor shaft; $w_{a}$ is the output speed of servo motor; $l_{a}$ is the position response; $J_{b}$ is the moment of inertia of the drive system; $f_{b}$ is the viscous friction coefficient of the drive system; $i$ is the transmission ratio; $P_{h}$ is the screw lead; $\eta$ is the mechanical transmission efficiency; $M_{c}$ is the quality of the piston rod; $f_{c}$ is the viscous friction coefficient of the piston rod; $F_{m}$ is the loading force.

3.2. Modeling and Simulation of the Load Simulation Servo System. Load simulation servo system is to control the output force of $100 \mathrm{t}$ hydraulic servo cylinder when the output of the piston rod is in the fixed constraint. The load simulation servo system is composed of oil sources, overflow valve, servo valve, and $100 \mathrm{t}$ hydraulic servo cylinder. The model is shown in Figure 6 which is built through adding hydraulic components in the library $[20,21]$. When the load instruction is $30 \mathrm{t}$, the experiment and simulation response curves are shown in Figure 7. The result indicates that the load response is particularly fast and stable.

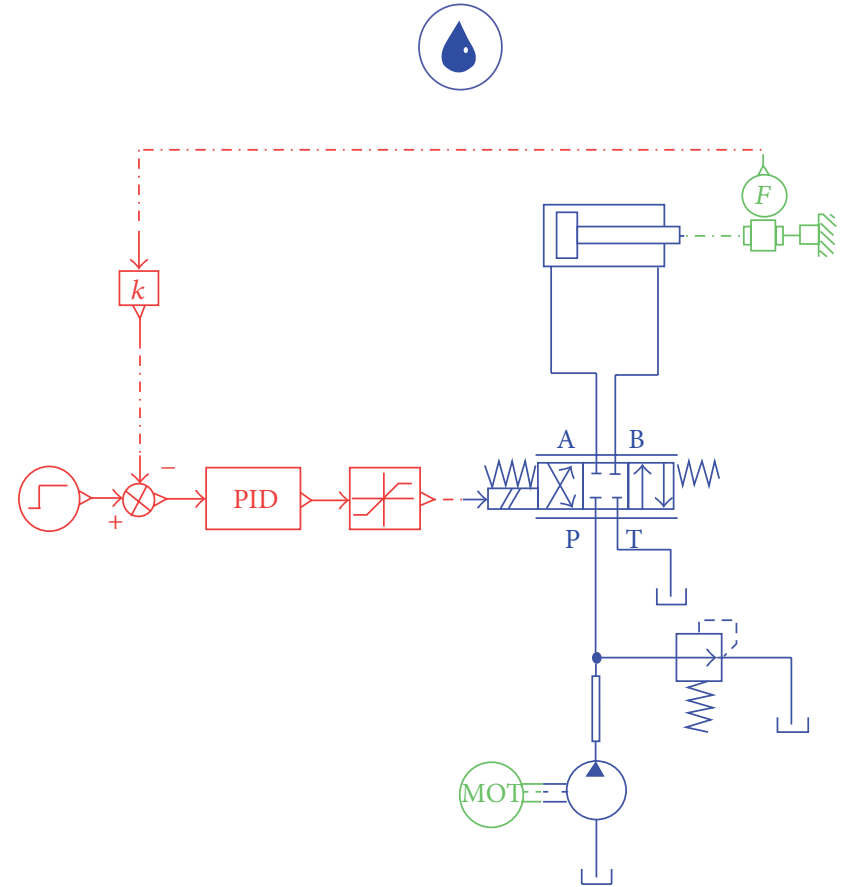

Figure 6: Model of load simulation system.

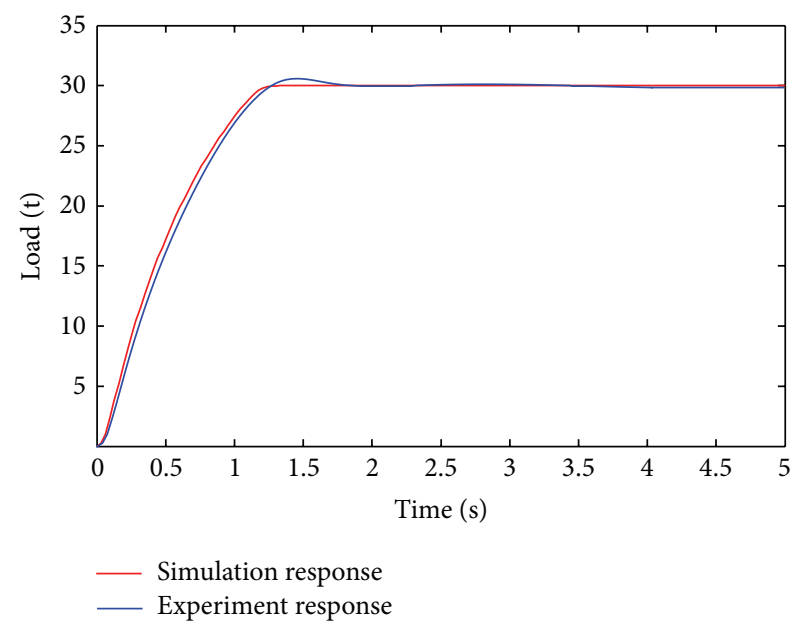

Figure 7: Response of the load simulation system. 


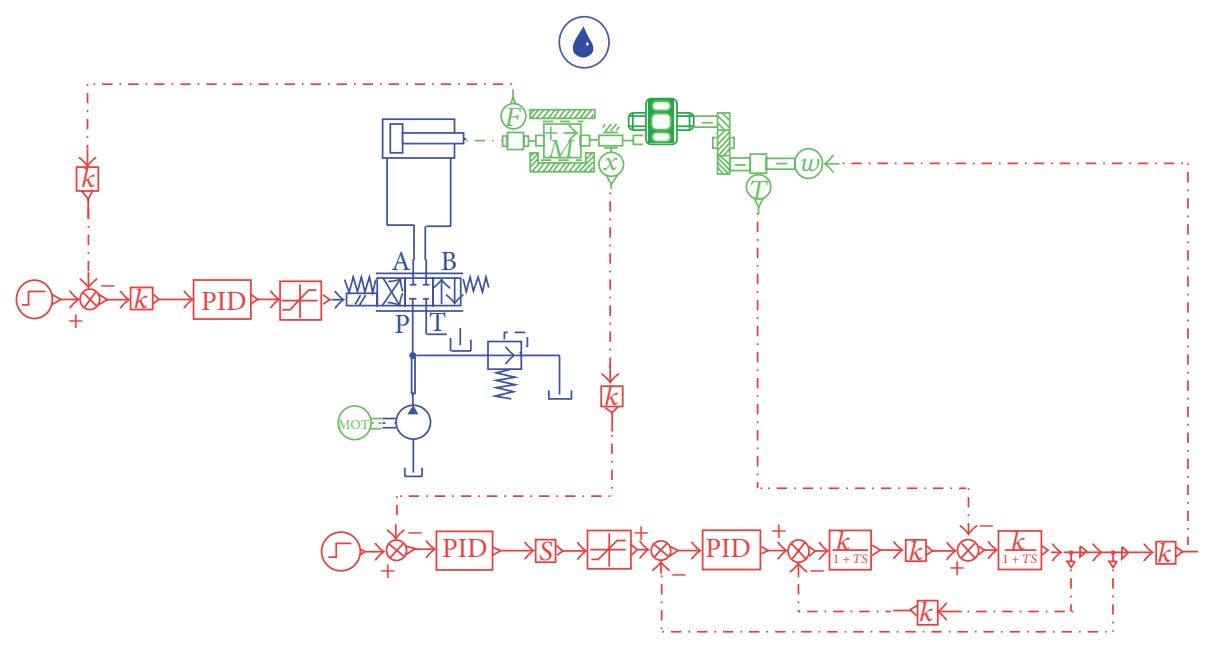

FIGURE 8: Model of the load simulator.

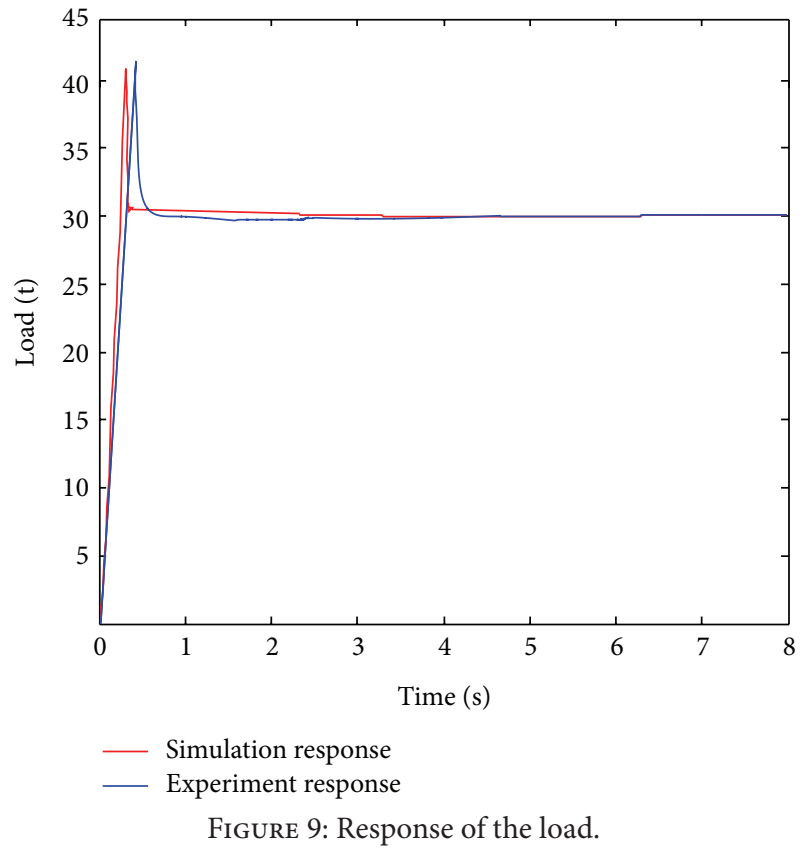

3.3. Modeling and Simulation of the Load Simulator. Figure 8 shows the model of the load simulator through combining position servo system with load simulation system. Figure 9 shows the load responses curves when the position instruction is set to $100 \mathrm{~mm}$ and load instruction is set to $30 \mathrm{t}$. The result indicates that the model can reflect real system.

\section{Reason of the Impact Load}

Figure 10 is the schematic diagram of the load simulator. The control current of the servo valve is $\pm 40 \mathrm{~mA}$. When the $30 \mathrm{t}$ electric cylinder extends its piston rod along the movement direction and $100 \mathrm{t}$ hydraulic servo cylinder provides $30 \mathrm{t}$ load, the output of control current in the servo controller is shown in Figure 11. The control current is $-40 \mathrm{~mA}$ in the initial stages of loading and servo valve core moves left in

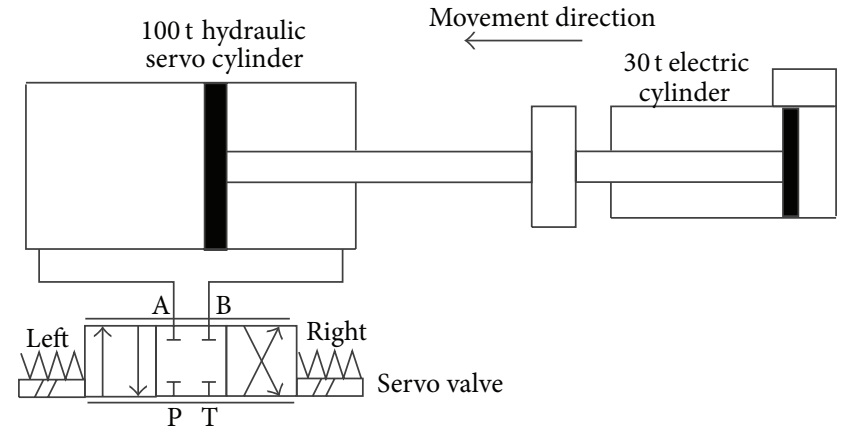

FIgURE 10: Schematic diagram of the load simulator.

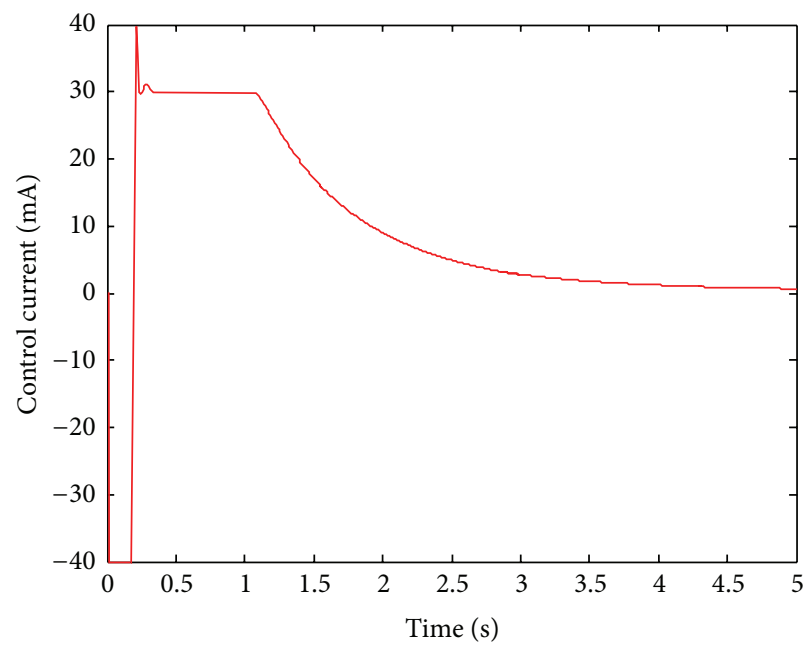

FIgURE 11: Control current.

order to provide $30 \mathrm{t}$ load. $\mathrm{P}$ gets connected to $\mathrm{A}$ and $\mathrm{B}$ gets connected to $\mathrm{T}$ at this moment. The pressure of $100 \mathrm{t}$ servo cylinder's rodless cavity is raised. Since $30 \mathrm{t}$ electric cylinder extends its piston rod along the movement direction, the piston of $100 \mathrm{t}$ servo cylinder is forced to move left. 


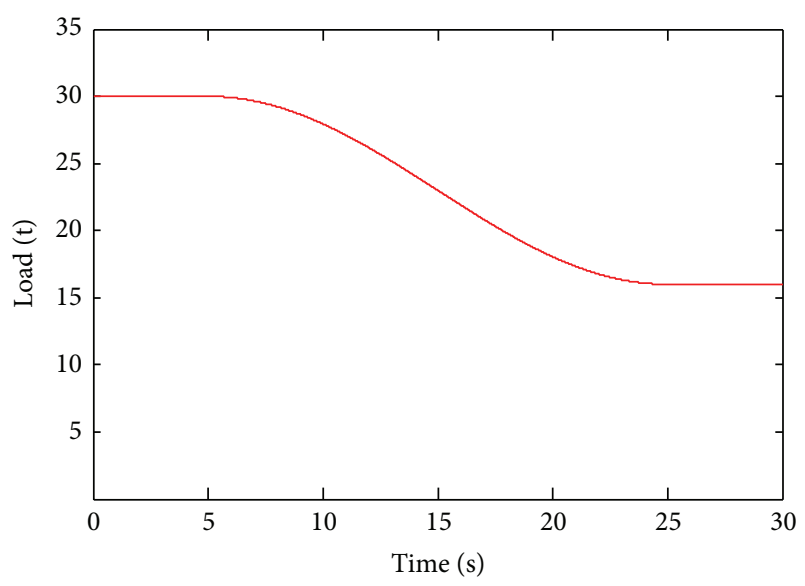

FIGURE 12: Control instruction of the $100 \mathrm{t}$ servo cylinder.

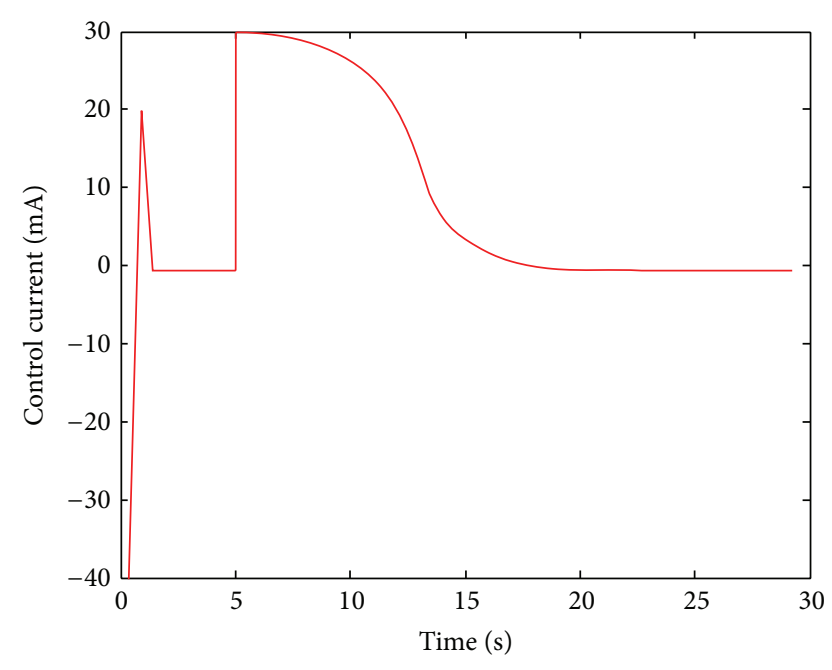

FIgURE 13: Control current.

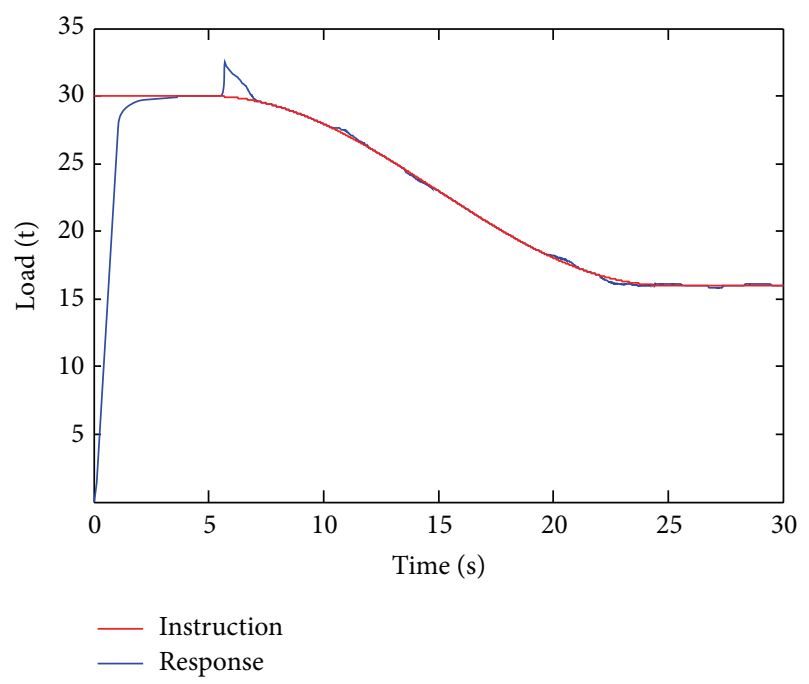

FIGURE 14: Load response of simulation.
The oil of A cannot be discharged by $\mathrm{P}$, which makes the pressure of the rodless cavity rise in $100 \mathrm{t}$ servo cylinder. The rod cavity will lead to negative pressure as B cannot suck oil by T. Therefore, the differential pressure between rodless cavity and rod cavity is expanding rapidly and the $40 \mathrm{t}$ impact load appears in the initial stage. Then, the control current becomes positive value and servo valve core moves right to make $\mathrm{P}$ get connected to $\mathrm{B}$ and $\mathrm{A}$ get connected to $\mathrm{T}$. The pressure of rodless cavity is kept by differential pressure between $\mathrm{A}$ and $\mathrm{T}$, which can provide $30 \mathrm{t}$ load. The instant rise and fall of control current will also produce impact load in the process of experiment because the servo valve works in the high pressure and large flow. Therefore, the changing rate of control current should not be too high.

\section{Inhibition Methods of Impact Load}

The impact load can seriously destroy the dynamic loading precision and even may damage the mechanical structure of electric cylinder, so we must adopt methods to suppress it. This paper presents some simple control algorithms based on structure invariance principle which is not only easily translated into computer language to be applied in the high precision real-time control system, but also can suppress the impact load.

5.1. Delay Control. The reason of initial impact load is the contradiction in movement direction between servo valve and $100 \mathrm{t}$ servo cylinder. We present delay control method which changes the loading instruction through extending action time of $30 \mathrm{t}$ loading (Figure 12). When the load reaches the scope of the loading precision, we start to issue control instructions of $30 \mathrm{t}$ electric cylinder. The control current is shown in Figure 13. When $100 \mathrm{t}$ servo cylinder completes loading, the control current becomes zero and servo valve core moves to the middle position. Then, the control current becomes positive value when $30 \mathrm{t}$ electric cylinder starts to move, which makes the movement direction of valve core keep consistency with $100 t$ servo cylinder. It can be seen from load response of simulation in Figure 14 that the impact load is reduced to $32 \mathrm{t}$. Although the impact load is suppressed to a large extent, it lasts about two seconds in the initial stage of $30 \mathrm{t}$ electric cylinder starting to move. Therefore, we present a control method of feedforward compensation based on speed.

5.2. Feedforward Compensation Based on Speed. The loading force is disturbed when $30 \mathrm{t}$ electric cylinder starts to move. The feedforward compensation based on speed can improve dynamic tracking ability and restrain interference [22, 23]. The speed of $30 \mathrm{t}$ electric cylinder multiplying by a scale factor will be a part of the control current of the servo valve. The new model of the load simulator is shown in Figure 15. When we apply these two methods into control program of the real system, the load response in the experiment is shown in Figure 16. It can be seen that when $100 \mathrm{t}$ servo cylinder and $30 \mathrm{t}$ electric cylinder start to be controlled, a small impact 


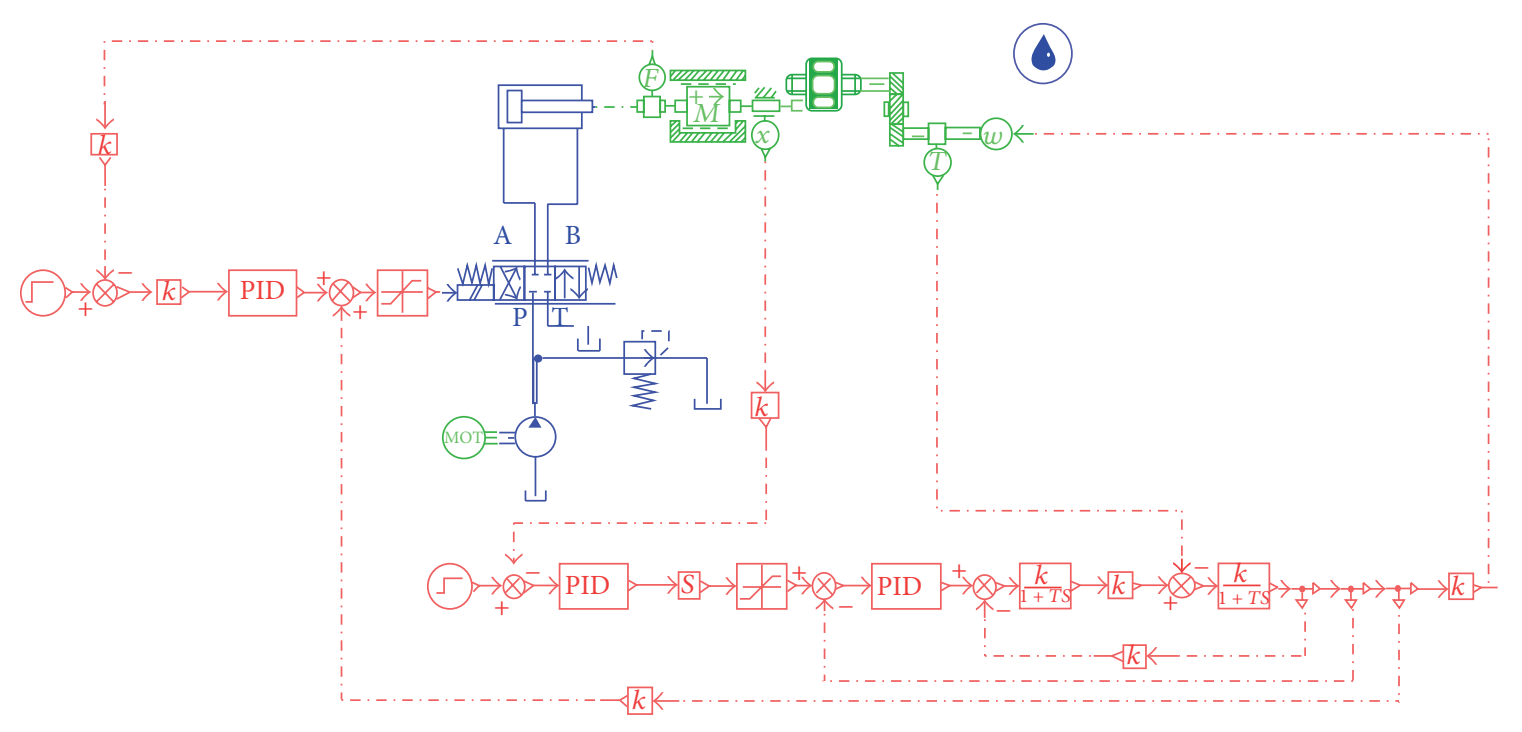

Figure 15: New model's load simulator.

load still exists. Therefore, we adopt a control method of incremental PID control algorithm.

5.3. Incremental PID Control Algorithm. The instant rise and fall of control current will also produce impact load in the process of experiment because the servo valve responds fast and works in the environment of high pressure and large flow. Therefore, the rate of control current should not be too high. The output of the incremental PID is $U(k)$ which can be achieved by the following:

$$
\begin{gathered}
U(k)=U(k-1)+\Delta U, \\
\Delta U=\Delta U p+\Delta U i+\Delta U d, \\
\Delta U p=K p(\Delta e(k)-\Delta e(k-1)), \\
\Delta U i=K i(\Delta e(k)-\Delta e(k-1)) \times T, \\
\Delta U d=\frac{K d(\Delta e(k)-2 \Delta e(k-1)+\Delta e(k-2))}{T},
\end{gathered}
$$

where $K_{p}, K_{i}$, and $K_{d}$ are parameters of the PID algorithm, $\Delta e(k)$ is the difference between expected and sampling value, and $T$ is the control period.

In order to improve the anti-interference ability of the system, we should not keep $K_{d}$ zero. $\Delta e(k)$ is bigger and $\Delta e(k-1), \Delta e(k-2)$ are both zero in the first control cycle and $T$ is very small, which makes the value of $K_{d}(\Delta e(k)-2 \Delta e(k-1)+$ $\Delta e(k-2)) / T$ very big. Therefore, we should make $K_{d}=0$ in the first control cycle and utilize adaptable value in the other control cycles.

When we adopt the above control methods, the load response of the load simulator in the experiment is shown in

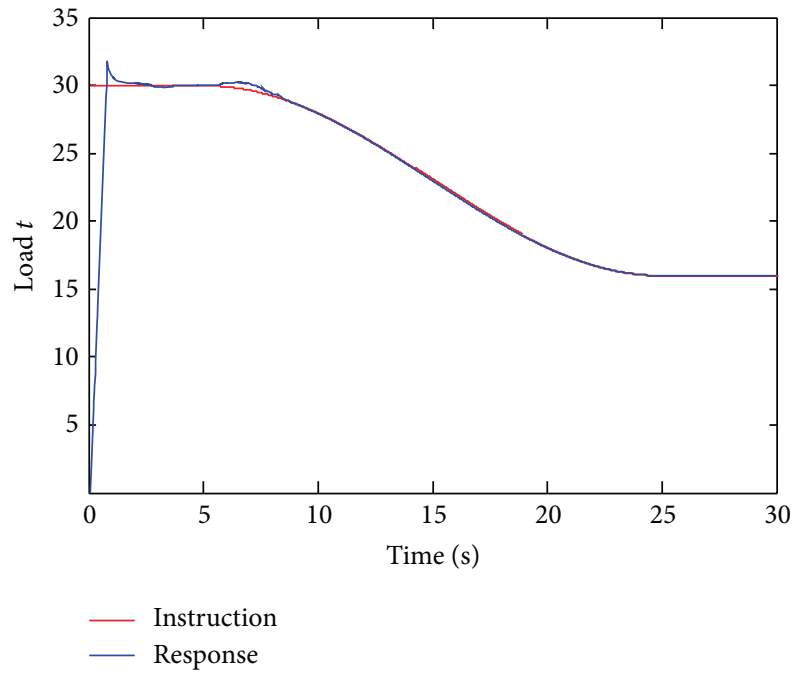

FIGURE 16: New model's load response in experiment.

Figure 17. It can be seen from Figures 2 and 17 that the impact load is suppressed in the process of dynamic loading.

\section{Conclusion}

The impact load of the large load simulator in the initial stage is caused by the contradiction in the direction of movement between servo valve and $100 \mathrm{t}$ servo cylinder. The experiment result indicates that the combined application of delay control, feedforward compensation based on speed, and incremental PID control algorithm based on structural invariability principle not only improves the load environment, but also suppresses the impact load, which is 


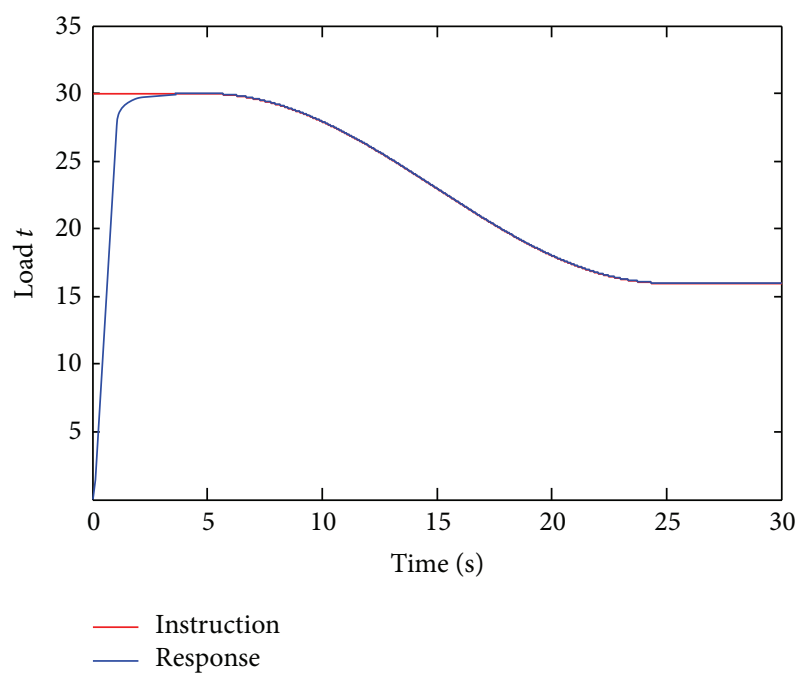

FIGURE 17: Response of the load simulator in experiment.

favorable for the application and generalization of the large load simulator.

\section{Conflict of Interests}

The authors declare that there is no conflict of interests regarding the publication of this paper.

\section{References}

[1] W. Zhanlin, Hydraulic Servo Control System, Beihang University Press, Beijing, China, 1987.

[2] Z. Jiao, Q. Hua, and X. Wang, "Evaluation system of load simulator," Chinese Journal of Mechanical Engineering, vol. 38, no. 11, pp. 26-30, 2002.

[3] L. K. Stewart, B. Durantb, J. Wolfsonc, and G. A. Hegemierb, "Experimentally generated high-g shock loads using Hydraulic Blast Simulator," International Journal of Impact Engineering, vol. 6, no. 9, pp. 86-94, 2014.

[4] D. H. Su and Y. Q. Wang, "Development of electro-hydraulic load simulator with high precise," in Proceedings of the 5th International Conference on Fluid Power Transmission and Control, pp. 281-285, Hangzhou, China, 2001.

[5] C. W. Wang, Z. X. Jiao, S. Wu, and Y. X. Shang, "An experimental study of the dual-loop control of electro-hydraulic load simulator," Chinese Journal of Aeronautics, vol. 26, no. 6, pp. 1586-1595, 2013.

[6] Y. Hao, L. Changchun, and C. Ce, "Simulation and experiment of electro-hydraulic servo systems load simulator," Chinese Hydraulics and Pneumatics, vol. 3, pp. 19-52, 2013.

[7] K. Zhou, Y. Li, and Y. Yunfeng, "Research of the hydraulic load simulator control," Science Technology and Engineering, vol. 35, no. 12, pp. 9523-9527, 2012.

[8] Z. Zhang, X. Liu, and J. Wang, "Robust $H_{\infty}$ sliding mode control with pole placement for a fluid power electrohydraulic actuator (EHA) system," International Journal of Advanced Manufacturing Technology, vol. 73, no. 5-8, pp. 1095-1104, 2014.
[9] Z. Jiao, Q. Hua, X. Wang, and S. Wang, "Compound control of electro-hydraulic load simulator," Chinese Journal of Mechanical Engineering, vol. 38, no. 2, pp. 685-689, 2002.

[10] H. Qing and J. Zongxia, "CRNN neural network control of the load simulator," Chinese Journal of Mechanical Engineering, vol. 38, no. 1, pp. 15-19, 2003.

[11] Z. Jiao and Q. Hua, "RBF neural network control on electrohydraulic load simulator," Chinese Journal of Mechanical Engineering, vol. 39, no. 1, pp. 10-14, 2003.

[12] Z. Yuan and L. Wang, "Compound compensator based on cerebellar model articulation controller for surplus torque in passive electric loading system," Journal of Tongji University, vol. 32, no. 5, pp. 685-689, 2004.

[13] L. Chenggong, J. Hongtao, and J. Zongxia, "Mechanism and suppression of extraneous torque of motor driver load simulator," Journal of Beijing University of Aeronautics and Astronautics, vol. 32, no. 2, pp. 204-208, 2006.

[14] H. Zhang and S. Yang, "On energy-to-peak filtering for nonuniformly sampled nonlinear systems: A Markovian Jump System Approach," IEEE Transactions on FUZZY System, vol. 22, no. 1, pp. 212-222, 2014.

[15] H. Zhang, X. Zhang, and J. Wang, "Robust gain-scheduling energy-to-peak control of vehicle lateral dynamics stabilization," Vehicle System Dynamics, pp. 309-338, 2014.

[16] X. Wencan, "Electric cylinder and air cylinder," Hydraulics Pneumatics \& Seals, vol. 24, no. 2, pp. 18-22, 2006.

[17] T. Ying, "The analysis on driving and force of electric cylinder," Heavy Machinery Science and Technology, vol. 13, no. 1, pp. 1014, 2007.

[18] X. Xie and H. Yang, "Model of servo motor in the position servo system," Journal of Beijing Institute of Technology, vol. 16, no. 3, pp. 323-326, 1996.

[19] F. Yongling, Modeling and Simulation Based on AMESim, Beihang University Press, Beijing, China, 2006.

[20] M. Changlin, H. Xianxiang, and H. Lin, "Simulation and optimization studies of electro-hydraulic servo system based on AMESim," Hydraulics Pneumatics \& Seals, vol. 1, pp. 32-34, 2006.

[21] W. Yafeng and G. Jun, "Research on simulation technique based on AMESim for aircraft hydraulic system," Journal of Shenyang University of Technology, vol. 29, no. 4, pp. 368-371, 2007.

[22] H. Zhang and J. Wang, "Combined feedback-feedforward tracking control for networked control systems with probabilistic delays," Journal of the Franklin Institute, Engineering and Applied Mathematics, vol. 351, no. 6, pp. 3477-3489, 2014.

[23] Z. Shuai, H. Zhang, J. Wang, and J. Li, "Lateral motion control for four-wheel-independent-drive electric vehicles using optimal torque allocation and dynamic message priority scheduling," Control Engineering Practice, pp. 55-66, 2014. 


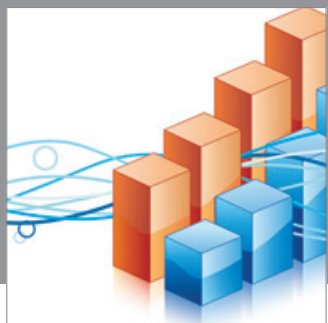

Advances in

Operations Research

mansans

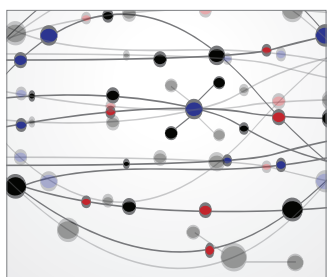

The Scientific World Journal
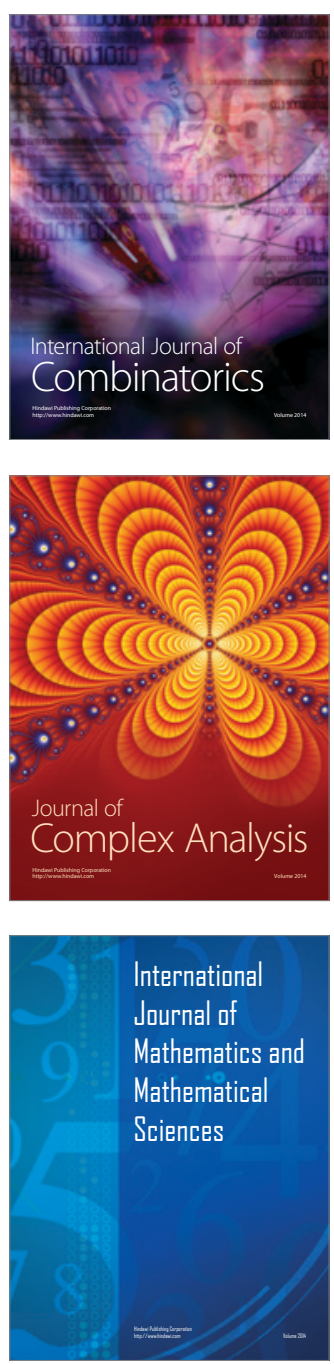
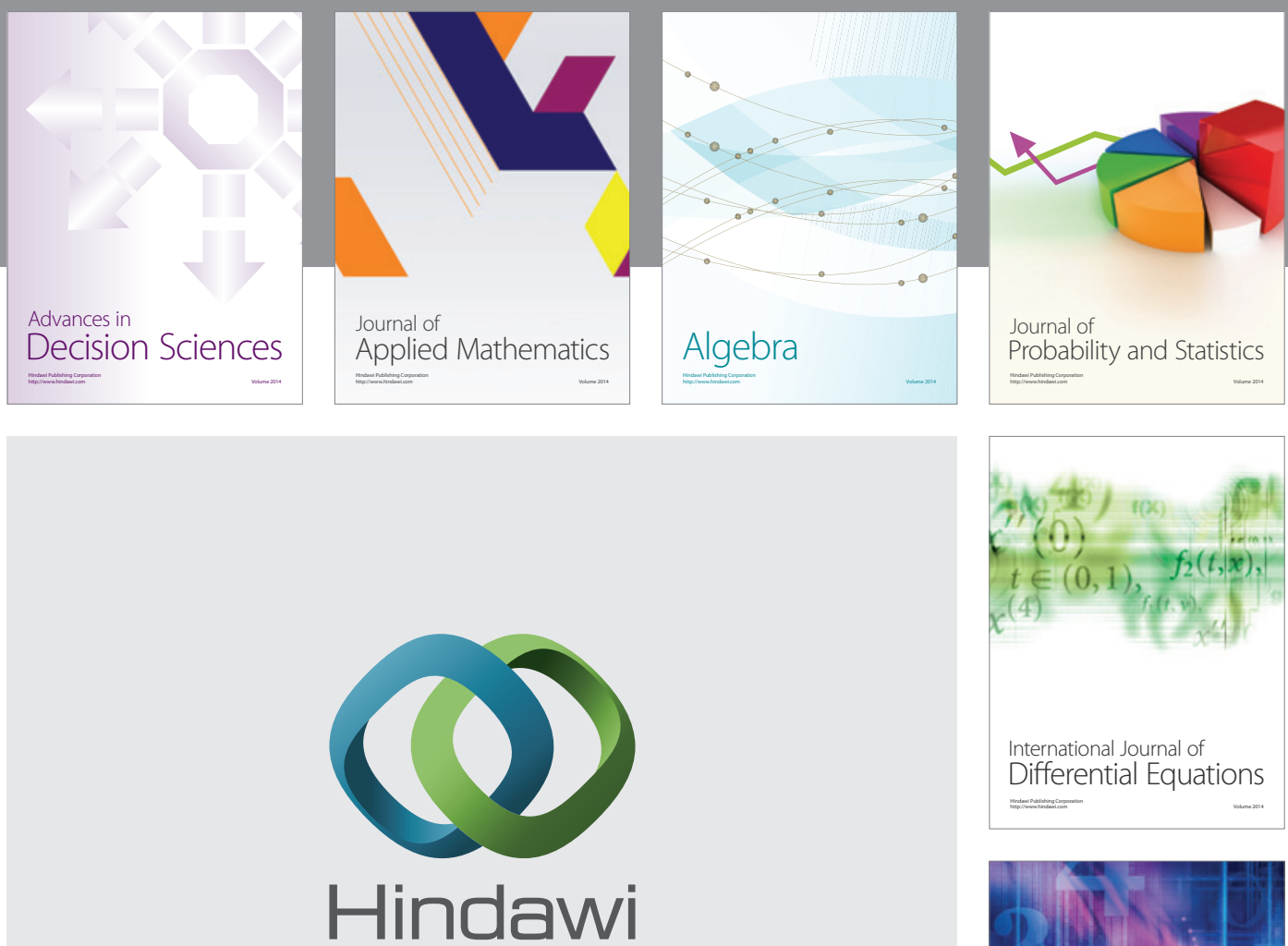

Submit your manuscripts at http://www.hindawi.com
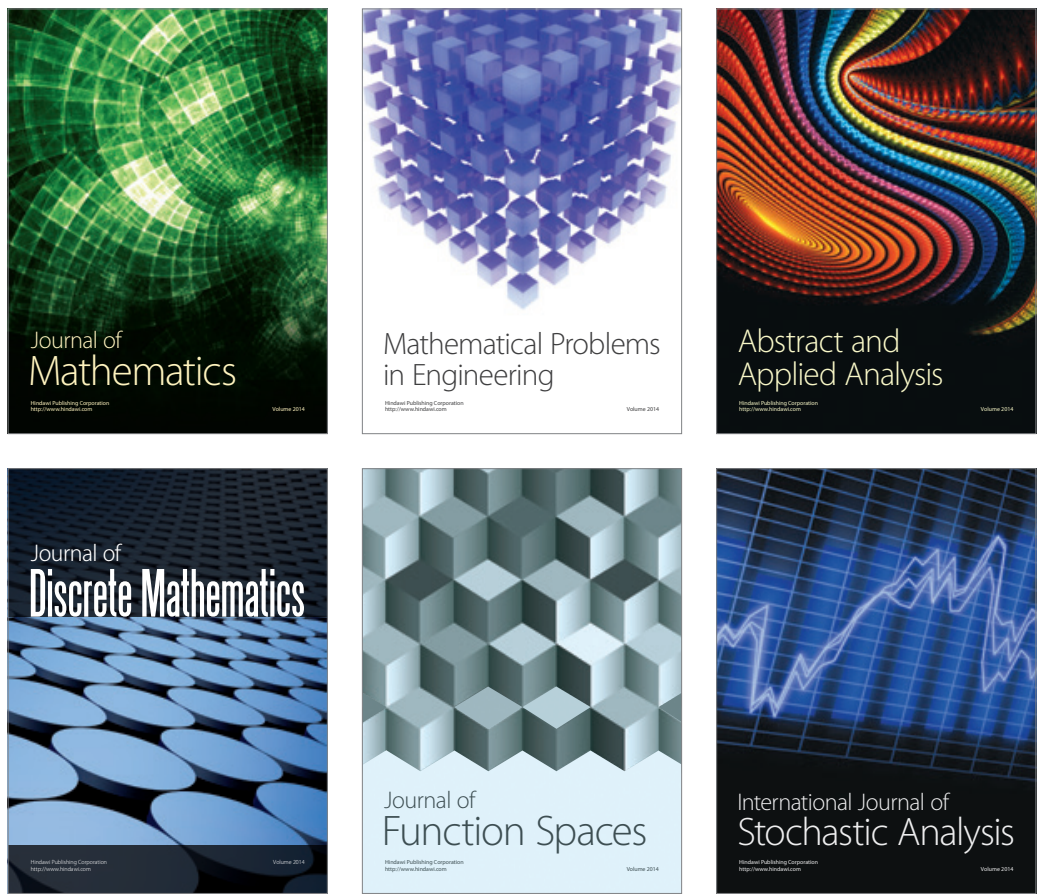

Journal of

Function Spaces

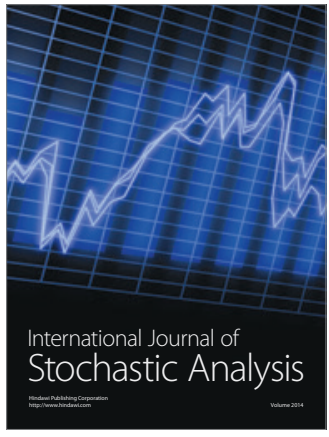

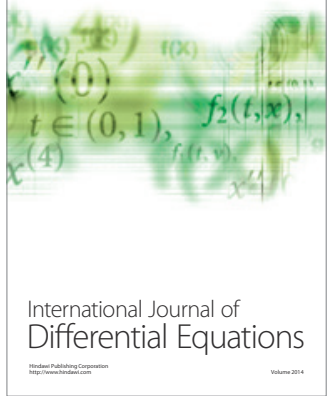
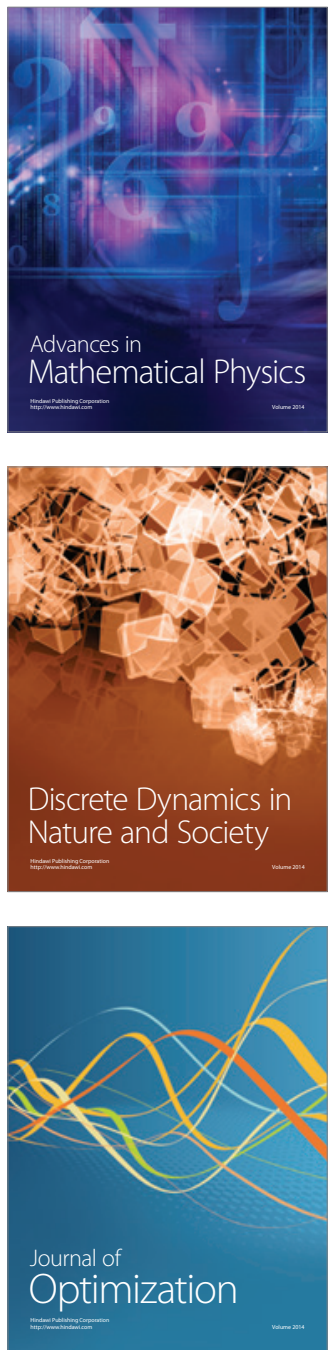